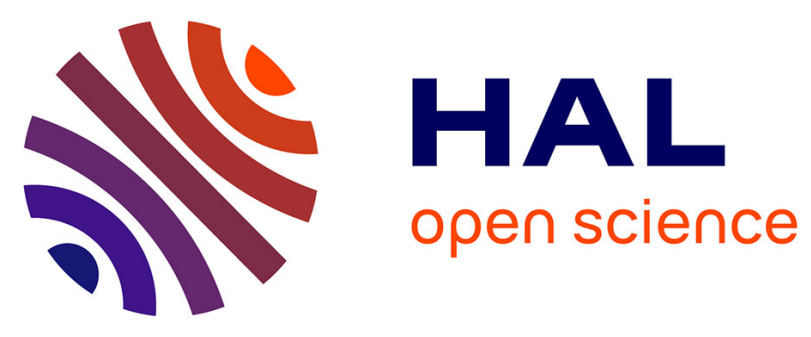

\title{
Prolonged transendothelial migration of human haematopoietic stem and progenitor cells (HSPCs) towards hydrogel-released SDF1
}

Lidia Sobkow, F. Philipp Seib, Ljupco Prodanov, Ina Kurth, Juliane Drichel, Martin Bornhäuser, Carsten Werner

\section{To cite this version:}

Lidia Sobkow, F. Philipp Seib, Ljupco Prodanov, Ina Kurth, Juliane Drichel, et al.. Prolonged transendothelial migration of human haematopoietic stem and progenitor cells (HSPCs) towards hydrogel-released SDF1. Annals of Hematology, 2011, 90 (8), pp.865-871. 10.1007/s00277-011-1155-

x . hal-00615420

\author{
HAL Id: hal-00615420 \\ https://hal.science/hal-00615420
}

Submitted on 19 Aug 2011

HAL is a multi-disciplinary open access archive for the deposit and dissemination of scientific research documents, whether they are published or not. The documents may come from teaching and research institutions in France or abroad, or from public or private research centers.
L'archive ouverte pluridisciplinaire HAL, est destinée au dépôt et à la diffusion de documents scientifiques de niveau recherche, publiés ou non, émanant des établissements d'enseignement et de recherche français ou étrangers, des laboratoires publics ou privés. 
Prolonged transendothelial migration of human haematopoietic stem and progenitor cells (HSPCs) towards hydrogel-released SDF-1

Lidia Sobkow 1,2,¥ F. Philipp Seib ${ }^{1,2}$, Ljupco Prodanov ${ }^{1}$, Ina Kurth ${ }^{1}$, Juliane Drichel ${ }^{1}$, Martin Bornhäuser $^{2}$,Carsten Werner ${ }^{1 *}$

${ }^{1}$ Leibniz Institute for Polymer Research Dresden, Max Bergmann Centre for Biomaterials Dresden, Hohe Str. 6, Dresden 01069, Germany; ${ }^{2}$ University Hospital Carl Gustav Carus, Technical University Dresden, Fetscher Str. 74, Dresden 01307, Germany

* Corresponding author: Prof. Carsten Werner; Tel.: 0049-(0) 3514658 532; Fax: 0049-(0) 3514658 533; email: werner@ipfdd.de

$¥$ Current address: Stony Brook University, Biochemistry and Cell Biology, Stony Brook, NY, USA

Keywords: HSPC, SDF1, Heparin, collagen, migration, gradient. 


\begin{abstract}
The therapeutic success of haematopoetic stem and progenitor cell (HSPC) transplantation is critically dependent on HSPC engraftment in the bone marrow. Gradients of stromal cell derived factor 1 (SDF1) direct HSPC homing both in vitro and vivo. Potentially, regulating delivery levels of exogenous SDF1 applied to the bone marrow could augment HSPC engraftment. Thus the aim of the present study was to revise the ability of biocompatible hydrogels to direct HSPC migration in vitro.

The delivery system of choice is based on heparin cross-linked with Collagen1. We confirm that hydrogel is capable to trap and release SDF1 and used it to generate protein gradient in transendothelial (Human Umbilical Vein Endothelial Cell - HUVEC) migration experiments. The use of SDF1 functionalised hydrogel to produce chemokine gradient revealed sustained and increased HSPC migration when compared to diffusible SDF1 controls.

In conclusion, regulating SDF1 gradients with heparin-containing hydrogels may offer valuable options to direct site-specific migration of HSPC.
\end{abstract}




\section{INTRODUCTION}

In healthy adults haematopoietic stem cells/progenitors (HSPCs) reside in the bone marrow microenvironment [1] and are able to rapidly respond to the specific demand of their progeny. Current concept defining stem cell niche identifies specific niches (and close interactions between them)for normal hematopoietic stem cell renewal and maintenance: one associated closely with the endosteal surface with self-renewal and quiescence related function, and the other one in close proximity to the vasculature that provides signals for HSPC motility/migration and differentiation [2-4] .

Accumulating evidence suggests that there is a close cross talk between those compartments and HSPC migration/location is in part dependent on the pre-conditioning regime the bone marrow compartment has been subjected to [3]. In spite of the still limited knowledge about molecular pathways governing HSPC homing to the bone marrow, there are attempts to manipulate the involved processes [5-9]. Indeed, the therapeutic success of HSPC transplantation is critically dependent on HSPC engraftment in the bone marrow [10-11] One of the key factors known to influence HSPC migration (in and out of the bone marrow) is stromal cell derived factor 1 (SDF1) [12].

As nicely reviewed by Liekens and colleagues [13], current classification system for chemokines places SDF-1 in the group of CXC class and the protein has been assigned the name CXCL12. CXCL12 interaction with CXCR4 receptor is extensively studied and it has been implicated in many biological events from embryonic and adult stem cell trafficking, through angiogenic processes and endothelial cells migration in ischemic tissue repair and tumors, to cancer cells migration and metastasis [13-14].

Several earlier studies described the adsorption of SDF1 to tissue culture plastic [15], heparin coated dishes [16-17], or fibronectin layers [18] with the aim to manipulate the migratory response of HSPC and/or the adhesion of T cells to immobilized SDF1. All of those studies used two-dimensional culture systems with limited SDF1 loading capacity that is not amenable for in vivo studies. None of these studies specifically aimed at designing release system that allowed the formation of SDF1 gradients in vivo.

In the current study we used Collagen1-Heparin based matrix [19] as a SDF1 delivery system. Collagen1-Heparin matrix was functionalized with SDF1 and tested for its ability to induce HSPC migration in vitro. 


\section{MATERIALS AND METHODS}

Preparation of Collagen1 - Heparin.

For the preparation of reconstituted Collagen type I based matrices, annealed PEMA (poly-ethylene maleic anhydride) thin films were used as the substrate for fibrillogenesis [19-21]. Collagen type I $(1.2 \mathrm{mg} / \mathrm{ml})$ (PureCol®, Inamed Biomaterials, Nutacon, Netherlands) supplemented with heparin $(0.4 \mathrm{mg} / \mathrm{ml})(14 \mathrm{kDa}$, sodium salt from porcine intestinal mucosa, Calbiochem, USA) was prepared as detailed previously [20]. For cell culture experiments the surface-bound matrices were UV sterilized for $30 \mathrm{~min}$. The thickness of swollen collagen heparin layer was determined by confocal microscopy to be $\sim 1 \mu \mathrm{m}$.

\section{Hydrogel functionalisation and release of SDF1}

All functionalisation studies were performed with substrate that was fixed in custom made immobilisation chambers with a nominal surface area of $1 \mathrm{~cm}^{2}$. To determine the amount of SDF1 in the system ${ }^{125}$ I labelled SDF1 was used. SDF1 (Strathman, Germany) was labelled with radioactive iodine ${ }^{125} \mathrm{I}$ (CHELATEC SAS, Nantes, France) by employing IodoBeads according to the manufacturer's instructions (IodoBeads, Pierce Biotechnology, USA). During the optimization we determined that SDF1 saturated substrate within $3 \mathrm{~h}$ ) thus for all subsequent experiments a $3 \mathrm{~h}$ immobilization time was used.

The selected solution concentration of $10 \mu \mathrm{g} / \mathrm{ml}$ and $1 \mu \mathrm{g} / \mathrm{ml}$ SDF1 were applied in volume of $266 \mu$ (i.e. 2600ng and 260ng of total protein respectively) to the respective substrate, immobilised for $3 \mathrm{~h}$ and subsequently washed three times with PBS or CellGro SCGM cell culture Medium (CellGenix, Germany). Surface associated radioactivity was quantified using a beta counter (Berthold Technologies, Germany) and the amount of protein immobilized was calculated. For release studies, samples were incubated with either PBS or CellGro SCGM Medium (CellGenix, Germany) and surface associated radioactivity was determined at the indicated time point.

Isolation of primary human cells 
The study was approved by the local institutional review board of the University Hospital, Technical University Dresden. Samples from granulocyte colony-stimulating factor (G-CSF) mobilised leukapheresis products were obtained from healthy donors after informed consent. CD133+ HSPC were isolated using immunomagnetic assisted selection (MACS, Miltenyi Biotech, Bergisch Gladbach, Germany) as previously described [22]. HSPC were placed in CellGro SCGM Medium (CellGenix, Germany) and allowed to recover over night $\left(37^{\circ} \mathrm{C}, 5 \% \mathrm{CO}_{2}\right)$ before commencing migration studies.

Human primary endothelial cells (HUVECs) were isolated in house from umbilical cord veins as previously described [23]. HUVEC were cultured in EC Medium containing supplement mix (Promo Cell, Germany) and $2 \%$ serum on transwell filters until confluency, and then used in the transendothelial migration experiment (detailed below). Labelling of HUVECs with the SDF1 polyclonal antibody (Abcam) showed that the protein is expressed internally in HUVECs (data no shown) which is consistent with previous reports [24]. However, we were not able to detect the presence of SDF1 in the conditioned culture medium by ELISA (detection limit $\sim 40 \mathrm{pg} / \mathrm{ml}$ ).

\section{Flow cytometry (FACS) of HSPC}

Migrating and non migrating cells were collected at 1h, 4h, 24h, 3days and 7days, counted and stained with anti-CXCR4-phycoerythrin-cy5 (PE-Cy5; BD Biosciences), anti-CD133-phycoerythrin (PE), antiCD38-fluoresceinisothiocyanat (FITC), anti-CD34-allophycocyanin (APC) and/or anti-CD34-FITC (all Miltenyi) according to manufacturers protocol and subjected to FACS analysis using a FACS Calibur with CELL Quest Software (Becton Dickinson, San Jose, USA). Data Analysis was done with the FlowJo (TreeStar Inc. USA) software. Analysis of expression profile of HSPC showed that all isolated cells expressed CD38 initially and population of CD133+CD34+CD38- cells is very small, often beyond abilities of standard MACS isolation kits [22].

\section{Transwell migration assays of HSPCs}

All migration experiments were performed in 24 well transwell plates (Corning, USA) with a $5 \mu$ m pore size filter. To generate a SDF1 gradient respective SDF1 loaded substrate was placed in the lower chamber. $15 \mathrm{~mm} \emptyset$ glass slide with SDF1-loaded biopolymer (prepared according to immobilization protocol detailed above) was placed in one well of 24-well-plate with surface facing up. $1 \mathrm{ml}$ of 
CellGROW medium was placed in each well containing SDF1-loaded biopolymer slide. HSPCs suspension $(100 \mu \mathrm{l})$ was placed on the filter and cells were allowed to migrate at $37^{\circ} \mathrm{C}, 5 \% \mathrm{CO}_{2}$ conditions.

Cultures were maintained in CellGro SCGM Medium (CellGenix, Germany) without cytokines and cultured at $37^{\circ} \mathrm{C}$ in a $5 \% \mathrm{CO}_{2}$ atmosphere. For migration experiment $3 \times 10^{5} \mathrm{HSPCs}$ (in $100 \mu \mathrm{l}$ ) were used per insert. Migration was determined after $1 \mathrm{~h}, 4 \mathrm{~h}, 24 \mathrm{~h}, 3$ days and 7 days. The medium from the lower chamber $(1 \mathrm{ml})$ was collected and migrated HSPC cells were counted. The medium in the lower chamber was immediately replaced with the fresh medium and HSPC cells were allowed to migrate until the next time point. The total number of HSPC migrated at each time point is calculated as cumulative value integrating all previous time points.

As a control $1 \mathrm{ml}$ of 500ng/ml SDF1 solution was placed in one well of 24-well-plate and HSPC were allowed to migrate. Furthermore, CellGrow Medium only was used to determined spontaneous HSPC migration through the membrane. To ensure that in our set up migration was indeed SDF1-induced, HSPC were incubated for 2 hours with 500ng/ml SDF1 with the CXCR4 antagonist AMD3100 prior to SDF1 migration assay [25].

\section{Colony forming unit assay}

HSPCs that migrated towards the SDF1 gradient were collected and CFU assay was performed according to standard protocol using a complete semi-solid CFU medium with cytokines/EPO (MethoCult, Stem Cell Technologies, Germany). After 14 days, the percentage of granulocyte (CFUG), granulocyte-macrophage (CF-GM), erythroid burst-forming units (BFU-E) and mixed colonies (CFU-GEMM) was determined. Two independent experiments with cells from different donors were performed.

\section{RESULTS}

SDF-1gradient and HSPC migration. The Collagen-1 - Heparin matrix showed loading efficiency at $26 \%$ for $10 \mu \mathrm{g} / \mathrm{ml}$ of loaded SDF1 and $32 \%$ for $1 \mu \mathrm{g} / \mathrm{ml}$ (Fig1). Samples were washed with cell culture medium to measure SDF1 protein release in our culture setup. The initial release of SDF1 to the medium was $470 \mathrm{ng}$ from gel loaded with $10 \mu \mathrm{g} / \mathrm{ml}$ of SDF1. This resulted in the amount of the 
protein in the medium to be in the same range (on the same level) as in the soluble control (500 $\mathrm{ng} / \mathrm{ml})$. The next release step was 10 times smaller, and each subsequent was minimal. In the gel loaded with $1 \mu \mathrm{g} / \mathrm{ml}$ the initial protein release was approximately $60 \mathrm{ng}$ with each subsequent medium change resulting in minimal SDF1 release.

Next, basal HSPC migration levels at 1,4, 24h and 3days were determined that to be $\sim 1,2,7$ and $8 \%$ respectively in the absence of stimulation. Migration of HSPCs towards soluble SDF1 $(500 \mathrm{ng} / \mathrm{ml})$ reached $9 \%$ after 3 days. Cells were allowed to migrate through the filter alone or through the confluent layer of HUVECs plated on the filter. (Fig2)

The specificity of this response was verified by blocking of the SDF1 receptors CXCR4 with AMD 3100 [25] that reduced migration to basal levels (data not shown).

HSPCs migration was subsequently studied up to 7 days. Collagen1-Heparin system was compared to control that employed diffusible SDF1 only $(500 \mathrm{ng} / \mathrm{ml})$. In the absence of endothelial lining (i.e. no HUVECS, sample SDF1(10) and SDF1(1)), samples reached more than $8 \%$ and over $12 \%$ of the cells migrating towards SDF1 gradient from gel loaded with $10 \mu \mathrm{g} / \mathrm{ml}$ and $1 \mu \mathrm{g} / \mathrm{ml}$ respectively after 7 days. Migration rate increasedto over $23 \%$ of migrating cells for SDF1 gradients from hydrogel loaded with both, $10 \mu \mathrm{g} / \mathrm{ml}$ and $1 \mu \mathrm{g} / \mathrm{ml}$ respectively in samples where HUVEC layer was present. (Fig2)

Substantial differences between the hydrogel system and the controls were evident from $24 \mathrm{~h}$ onwards. At early time points ( 1 and $4 \mathrm{~h}$ ) there were no differences between the systems. Sample with $1 \mu \mathrm{g} / \mathrm{ml}$ immobilized SDF1 and HUVECS (SDF1(1)-H on Fig2) however, showed migration in the range of $8 \%$ already after $1 \mathrm{~h}$, and increased to $23 \%$ of migrated cells in total after 7 days. Control cultures that contained no SDF1 also showed basal migration levels that were less than for cultures that contained diffusible SDF1. At time points $24 \mathrm{~h}$ and $3 \mathrm{~d}$, migration levels for the controls were comparable for cultures containing diffusible SDF1, whereas we observed boost of cell migration towards SDF1 released from hydrogel layers. ANOVA statistics was applied to test the significance of observed differences and it resulted in $p$ values below 0.002 .

Clonogenicity and phenotype.To test whether long term culture of hematopoietic stem cells subjected to SDF1 gradient will have an effect on their clonogenicity and differentiation potential we performed colony forming unit assay. We used Collagen1-Heparin hydrogel loaded with $1 \mu \mathrm{g} / \mathrm{ml}$ SDF1 for the 
long term profiling of migrating HSPCs upon exposure to SDF1 gradient (Fig.3.B). The non-migrating (NM) control tended to contain more CFU-M and CFU-GM colonies than those that migrated within first $4 \mathrm{~h}$. Furthermore, the contribution of erythroid colonies in the control group was only $2 \%$ whereas hydrogel samples at 4h, 24h and 72h contained 13, 10 and 7\% erythroid colonies, respectively. Even after 7 days of exposure to the SDF1 gradient cells were able to generate CFU-GM and CFU-GEMM, suggesting that our culture set-up was able to maintain clonogenic hematopoietic progenitor cells for at least one week. At all time points FACS analysis confirmed the expression of CD34, CD133 and CXCR4 (CD184) on the HSPC in vitro suggesting that the progeny generated during the observation period was able to follow the persistent chemokine gradient. (Fig3.A)

\section{DISCUSSION}

Previous studies by us and others could show that hydrogel systems are applicable for a number of tissue engineering applications including strategies aimed at neuronal and cardiac tissue repair [26-29] In particular the (controlled) release of growth factors and morphogens are critical parameters in this process as they (in part) are attributed to regulate the migration and mobilisation of resident stem/progenitor cells.

Sulphated GAGs, in particular heparan sulphate, exhibit a particularly high affinity to SDF1 and have been reported to support presentation of SDF1 to the vascular lumen in the stem cell niche [16-17, 30]. It is also known that heparin is a natural protector of SDF1 [31] that prevents the protein from degradation. Therefore, sulphated polysaccacharides define a promising starting point for the design of biomimetic matrices capable of modulating SDF1 gradients. The migration experiments performed with the matrix-bound SDF1 samples described above showed the highest migratory response of HSPC to SDF1 gradients in vitro reported so far. The control samples with pure medium and soluble control show migration below $10 \%$, which is consistent with previous reports describing similar assays [32]. However, heparin containing matrix influences the SDF1 retention in ways resulting in longer lasting gradient formation and successful chemotactic control of HSPC. Presence of HUVEC on the transwell filter, with their own ECM and its ability to bind and present SDF1 [16] and the ability to process and re-secrete functional SDF1 [33] was found to further enhance the migratory response of HSPC in the investigated systems. This could explain the effect that we observe for sample SDF1(1)-H on Fig2, 
where small amounts of released SDF1 in the presence of HUVEC supporting layer cause increased HSPC migration. Referring to the current understanding of the hematopoietic microenvironment, we consider the transendothelial migration experiment as a representative in-vitro system modelling some aspects of the bone marrow 'niche': HUVEC growing on the filter mimic may represent the endothelial lining of bone marrow sinusoids through which HSPC have to pass to reach the peri-vascular niche. By modulating the immobilized amount of SDF1 we show that the migratory responses of HSPC could be maintained over time periods of at least 7 days. Presence of clonogenic progenitors with minimal changes in phenotype after 7 days in culture validates the supportive role of HUVEC in our system. Another interesting option of the reported SDF1 releasing polymer matrices concerns possible in vivo applications where local accumulation of hematopoietic progenitors would be desirable. Here, long term SDF1 release combined with additional biomolecular functionalization may open up new therapeutic avenues.

Hematopietic progenitor cells migrate selectively to the SDF-1 gradient [34]. It has been already described that functional CXCL12-CXCR4 axis is essential for proper mobilisation vs quiescence balance of HSCs in the bone marrow [35-36]. This phenomenon can be used as a main regulatory mechanism in stem cell transplantations and therapies. Since many stem and progenitor cells express CXCR4 receptor, and are known to respond to SDF-1 gradient [37], site-targeted, artificially elevated levels of SDF-1 (as shown here) are attractive tool to direct stem cells migration and homing to the required site e.g. bone marrow.

The field on a fast track for bioengineered matrices containing biologically relevant molecules is tissue repair and regeneration. Hypoxia and tissue damage causes elevation of HIF-1 in endothelial cells, which in turn causes increase of SDF1 expression chemo-attracting CXCR4+ tissue specific stem cells to participate in the regeneration process [38-39]. Again, artificially elevated levels of SDF1 limited to the site of interest can enhance therapy and limit potentially damaging preparatory treatments (e.g. radiation, invasive surgery). The tissue repair process can be enhanced by angiogenetic properties of CXCL12-CXCR4 axis ([40] and reviewed in [13]) in case of the hindlimb ischemia [41], stroke and heart myocardial infarction[42-43] or liver damage [44]. Collagen-1-Heparin matrix immobilisation of SDF-1 can provide such a tool for site-targeted and localized elevation of SDF-1. 
In summary, we describe SDF1 gradients from heparin-based polymer matrix which is biologically natural and permits the production of long lasting SDF1 gradients in vitro. The results provide a base for the use of chemokine gradients to control HSPC in tissue engineering strategies in vitro and in vivo. We have been able to show in vitro, that SDF1 functionalised hydrogel have the potential to support HSPC migration well above levels seen for diffusible SDF1. It remains to be seen if such hydrogel based system applied in vivo could also support an increased HSPC homing into bone marrow following stem cell transplantation.

Support and Financial Disclosure Declaration: Authors declare no competing financial interests.

\section{ACKNOWLEDGEMENTS}

This work was supported by the Leibniz Association (Senatswettbewerb LS, MB and CW), the Deutsche Forschungsgemeinschaft, "Collaborative Research Centre: Cells into tissues- stem cell and progenitor commitment and interactions during tissue formation" (SFB 655, Dresden, FPS, MB and CW) and the Centre for Regenerative Therapies Dresden (DFG Research Centre and Cluster of Excellence). 


\section{FIGURE LEGENDS}

Figure 1. SDF1 functionalisation of Collagen1 - Heparin substrate. Two different solution concentrations were used $(10 \mu \mathrm{g} / \mathrm{ml}$ and $1 \mu \mathrm{g} / \mathrm{ml})$ to functionalise substrate with SDF1. Bars represent the amount of SDF1 immobilized initially on the surface (Initial) and after 1, 2, and 3 washing steps respectively. Samples were washed with cell culture medium and the amount of surface associated ${ }^{125} \mathrm{I}$ SDF1 radioactivity was measured. Each condition was tested in at least 5 separate experiments in triplicate.

Figure 2. Migration of human haematopoetic stem and progenitor cells (HSPCs) in response to SDF1. Enriched HSPCs were added to the upper chamber and allowed to migrate into the receiver chamber in the presence and absence of SDF1. Cells were migrating through the filter alone or endothelial lining of HUVECs monolayer cultivated on the filter. Specificity of SDF1 dependant migration was measured by addition of AMD3100 to the medium (data not shown). Either diffusible soluble SDF1 (500ng/ml) or SDF1 functionalised hydrogels were as a SDF-1 source. Abbreviations: SDF1(10) or SDF1(1) surface loaded with SDF1 solution of $10 \mu \mathrm{g} / \mathrm{ml}$ or $1 \mu \mathrm{g} / \mathrm{ml}$ respectively; H - HUVECs monolayer on the filter; $500 \mathrm{ng} / \mathrm{ml}$ - concentration of soluble SDF1 (500ng/ml) in CellGROW medium; ctrl - control, culture medium without SDF1. * ANOVA statistical test was applied resulting in $\mathrm{p} \leq<0.002$.

Figure 3 . Characterisation of progenitor cells from migration assay . FACS and CFU analysis of migrating cells. A. Cells from the lower compartment in the migration assay were collected at $1 \mathrm{~h}, 4 \mathrm{~h}$, 24, 3d, 7d, stained against the CD133, CD34, CD38 and CD184(CXCR4). Non-migrating cells were also subjected to the FACS analysis showing the same expression profile (not shown). B. The same cells were analysed for clonogenicity and potential to differentiate to different hematopoietic lineages. Graph shows differentiation potential of migrated cells at different time points and non-migrated (N-M) cells after 7 days. Assay was performed for two donor samples in triplicate for each condition. 


\section{Literature:}

[1] Lane SW, Scadden DT, Gilliland DG. The leukemic stem cell niche: current concepts and therapeutic opportunities. Blood. 2009;114:1150-1157.

[2] Lymperi S, Ferraro F, Scadden DT. The HSC niche concept has turned 31. Has our knowledge matured? Ann N Y Acad Sci. 2010;1192:12-18.

[3] Xie $Y$, Yin T, Wiegraebe W, et al. Detection of functional haematopoietic stem cell niche using real-time imaging. Nature. 2009;457:97-101.

[4] Nie Y, Han YC, Zou YR. CXCR4 is required for the quiescence of primitive hematopoietic cells. J Exp Med. 2008;205:777-783.

[5] Dar A, Kollet O, Lapidot T. Mutual, reciprocal SDF-1/CXCR4 interactions between hematopoietic and bone marrow stromal cells regulate human stem cell migration and development in NOD/SCID chimeric mice. Exp Hematol. 2006;34:967-975.

[6] Lapidot T, Dar A, Kollet O. How do stem cells find their way home? Blood. 2005;106:1901-1910.

[7] Lapidot T, Kollet O. The essential roles of the chemokine SDF-1 and its receptor CXCR4 in human stem cell homing and repopulation of transplanted immune-deficient NOD/SCID and NOD/SCID/B2m(null) mice. Leukemia. 2002;16:1992-2003.

[8] Peled A, Kollet $O$, Ponomaryov $T$, et al. The chemokine SDF-1 activates the integrins LFA-1, VLA-4, and VLA-5 on immature human CD34(+) cells: role in transendothelial/stromal migration and engraftment of NOD/SCID mice. Blood. 2000;95:3289-3296.

[9] Waskow C, Madan V, Bartels S, Costa C, Blasig R, Rodewald HR. Hematopoietic stem cell transplantation without irradiation. Nat Methods. 2009;6:267-269.

[10] Tyndall A, Fassas A, Passweg J, et al. Autologous haematopoietic stem cell transplants for autoimmune disease--feasibility and transplant-related mortality. Autoimmune Disease and Lymphoma Working Parties of the European Group for Blood and Marrow Transplantation, the European League Against Rheumatism and the International Stem Cell Project for Autoimmune Disease. Bone Marrow Transplant. 1999;24:729-734.

[11] Almeida-Porada G, Flake AW, Glimp HA, Zanjani ED. Cotransplantation of stroma results in enhancement of engraftment and early expression of donor hematopoietic stem cells in utero. Experimental Hematology. 1999;27:1569-1575.

[12] Hattori K, Heissig B, Rafii S. The regulation of hematopoietic stem cell and progenitor mobilization by chemokine SDF-1. Leuk Lymphoma. 2003;44:575-582.

[13] Liekens S, Schols D, Hatse S. CXCL12-CXCR4 Axis in Angiogenesis, Metastasis and Stem Cell Mobilization. Curr Pharm Des. 2010.

[14] Sun X, Cheng G, Hao M, et al. CXCL12 / CXCR4 / CXCR7 chemokine axis and cancer progression. Cancer Metastasis Rev. 2010;29:709-722.

[15] DiVietro JA, Brown DC, Sklar LA, Larson RS, Lawrence MB. Immobilized stromal cellderived factor-1alpha triggers rapid VLA-4 affinity increases to stabilize lymphocyte tethers on VCAM-1 and subsequently initiate firm adhesion. J Immunol. 2007;178:3903-3911.

[16] Netelenbos T, van den Born J, Kessler FL, et al. Proteoglycans on bone marrow endothelial cells bind and present SDF-1 towards hematopoietic progenitor cells. Leukemia. 2003;17:175-184.

[17] Netelenbos T, Zuijderduijn S, Van Den Born J, et al. Proteoglycans guide SDF-1induced migration of hematopoietic progenitor cells. J Leukoc Biol. 2002;72:353-362.

[18] Pelletier AJ, van der Laan LJ, Hildbrand P, et al. Presentation of chemokine SDF-1 alpha by fibronectin mediates directed migration of T cells. Blood. 2000;96:2682-2690. 
[19] Salchert K, Oswald J, Streller U, Grimmer M, Herold N, Werner C. Fibrillar collagen assembled in the presence of glycosaminoglycans to constitute bioartificial stem cell niches in vitro. J Mater Sci Mater Med. 2005;16:581-585.

[20] Salchert K, Streller U, Pompe T, Herold N, Grimmer M, Werner C. In vitro reconstitution of fibrillar collagen type $\mathrm{I}$ assemblies at reactive polymer surfaces. Biomacromolecules. 2004;5:1340-1350.

[21] Pompe $T$, Zschoche $S$, Herold $N$, et al. Maleic anhydride copolymers--a versatile platform for molecular biosurface engineering. Biomacromolecules. 2003;4:1072-1079.

[22] Freund D, Oswald J, Feldmann S, Ehninger G, Corbeil D, Bornhauser M. Comparative analysis of proliferative potential and clonogenicity of MACS-immunomagnetic isolated CD34+ and CD133+ blood stem cells derived from a single donor. Cell Prolif. 2006;39:325332.

[23] Kohler T, Plettig R, Wetzstein W, et al. Defining optimum conditions for the ex vivo expansion of human umbilical cord blood cells. Influences of progenitor enrichment, interference with feeder layers, early-acting cytokines and agitation of culture vessels. Stem Cells. 1999;17:19-24.

[24] Salvucci O, Yao L, Villalba S, Sajewicz A, Pittaluga S, Tosato G. Regulation of endothelial cell branching morphogenesis by endogenous chemokine stromal-derived factor-1. Blood. 2002;99:2703-2711.

[25] Rosenkilde MM, Gerlach LO, Jakobsen JS, Skerlj RT, Bridger GJ, Schwartz TW. Molecular mechanism of AMD3100 antagonism in the CXCR4 receptor: transfer of binding site to the CXCR3 receptor. J Biol Chem. 2004;279:3033-3041.

[26] Freudenberg U, Hermann A, Welzel PB, et al. A star-PEG-heparin hydrogel platform to aid cell replacement therapies for neurodegenerative diseases. Biomaterials. 2009;30:5049-5060.

[27] Tabesh H, Amoabediny G, Nik NS, et al. The role of biodegradable engineered scaffolds seeded with Schwann cells for spinal cord regeneration. Neurochem Int. 2009;54:73-83.

[28] Jawad H, Lyon AR, Harding SE, Ali NN, Boccaccini AR. Myocardial tissue engineering. Br Med Bull. 2008;87:31-47.

[29] Spadaccio C, Chello M, Trombetta M, Rainer A, Toyoda Y, Genovese JA. Drug releasing systems in cardiovascular tissue engineering. J Cell Mol Med. 2009;13:422-439.

[30] Mbemba E, Gluckman JC, Gattegno L. Glycan and glycosaminoglycan binding properties of stromal cell-derived factor (SDF)-1alpha. Glycobiology. 2000;10:21-29.

[31] Sadir R, Imberty A, Baleux F, Lortat-Jacob H. Heparan sulfate/heparin oligosaccharides protect stromal cell-derived factor-1 (SDF-1)/CXCL12 against proteolysis induced by CD26/dipeptidyl peptidase IV. J Biol Chem. 2004;279:43854-43860.

[32] Mohle R, Moore MA, Nachman RL, Rafii S. Transendothelial migration of CD34+ and mature hematopoietic cells: an in vitro study using a human bone marrow endothelial cell line. Blood. 1997;89:72-80.

[33] Dar A, Goichberg P, Shinder V, et al. Chemokine receptor CXCR4-dependent internalization and resecretion of functional chemokine SDF-1 by bone marrow endothelial and stromal cells. Nat Immunol. 2005;6:1038-1046.

[34] Wright DE, Bowman EP, Wagers AJ, Butcher EC, Weissman IL. Hematopoietic stem cells are uniquely selective in their migratory response to chemokines. J Exp Med. 2002;195:1145-1154.

[35] Petit I, Szyper-Kravitz M, Nagler A, et al. G-CSF induces stem cell mobilization by decreasing bone marrow SDF-1 and up-regulating CXCR4. Nat Immunol. 2002;3:687-694. 
[36] Broxmeyer HE, Orschell CM, Clapp DW, et al. Rapid mobilization of murine and human hematopoietic stem and progenitor cells with AMD3100, a CXCR4 antagonist. J Exp Med. 2005;201:1307-1318.

[37] Bleul CC, Fuhlbrigge RC, Casasnovas JM, Aiuti A, Springer TA. A highly efficacious lymphocyte chemoattractant, stromal cell-derived factor 1 (SDF-1). J Exp Med. 1996;184:1101-1109.

[38] Ceradini DJ, Kulkarni AR, Callaghan MJ, et al. Progenitor cell trafficking is regulated by hypoxic gradients through HIF-1 induction of SDF-1. Nat Med. 2004;10:858-864.

[39] Ratajczak MZ, Kucia M, Reca R, Majka M, Janowska-Wieczorek A, Ratajczak J. Stem cell plasticity revisited: CXCR4-positive cells expressing mRNA for early muscle, liver and neural cells 'hide out' in the bone marrow. Leukemia. 2004;18:29-40.

[40] Chen $T$, Bai $H$, Shao $Y$, et al. Stromal cell-derived factor-1/CXCR4 signaling modifies the capillary-like organization of human embryonic stem cell-derived endothelium in vitro. Stem Cells. 2007; 25:392-401.

[41] Zemani F, Silvestre JS, Fauvel-Lafeve F, et al. Ex vivo priming of endothelial progenitor cells with SDF-1 before transplantation could increase their proangiogenic potential. Arterioscler Thromb Vasc Biol. 2008;28:644-650.

[42] Yu J, Li M, Qu Z, Yan D, Li D, Ruan Q. SDF-1/CXCR4-mediated migration of transplanted bone marrow stromal cells toward areas of heart myocardial infarction through activation of PI3K/Akt. J Cardiovasc Pharmacol. 2010;55:496-505.

[43] Paczkowska E, Kucia M, Koziarska D, et al. Clinical evidence that very small embryonic-like stem cells are mobilized into peripheral blood in patients after stroke. Stroke. 2009;40:1237-1244.

[44] Kollet O, Shivtiel S, Chen YQ, et al. HGF, SDF-1, and MMP-9 are involved in stressinduced human CD34+ stem cell recruitment to the liver. J Clin Invest. 2003;112:160-169. 


\section{$10 \mu \mathrm{g} / \mathrm{ml}$}

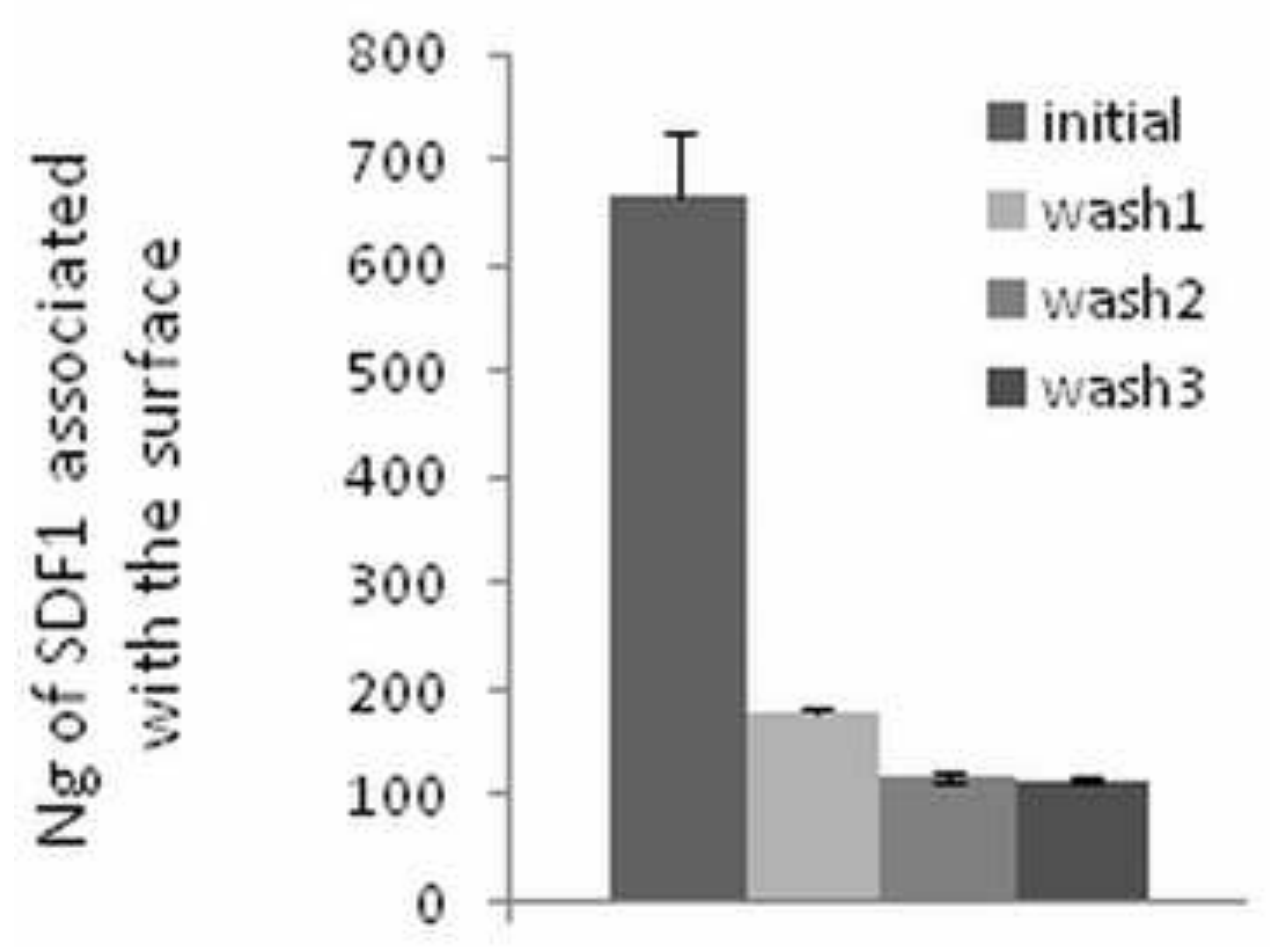

\section{$1 \mu \mathrm{g} / \mathrm{ml}$}

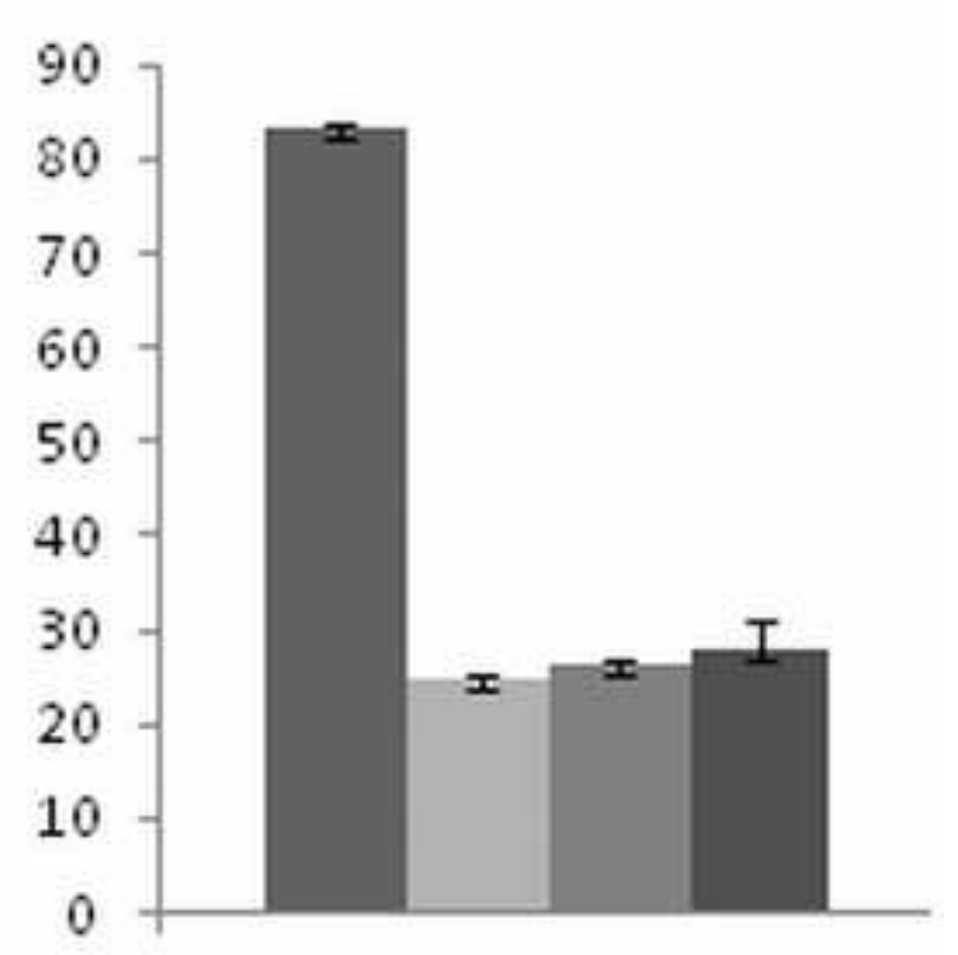


Figure
Click here to download high resolution image

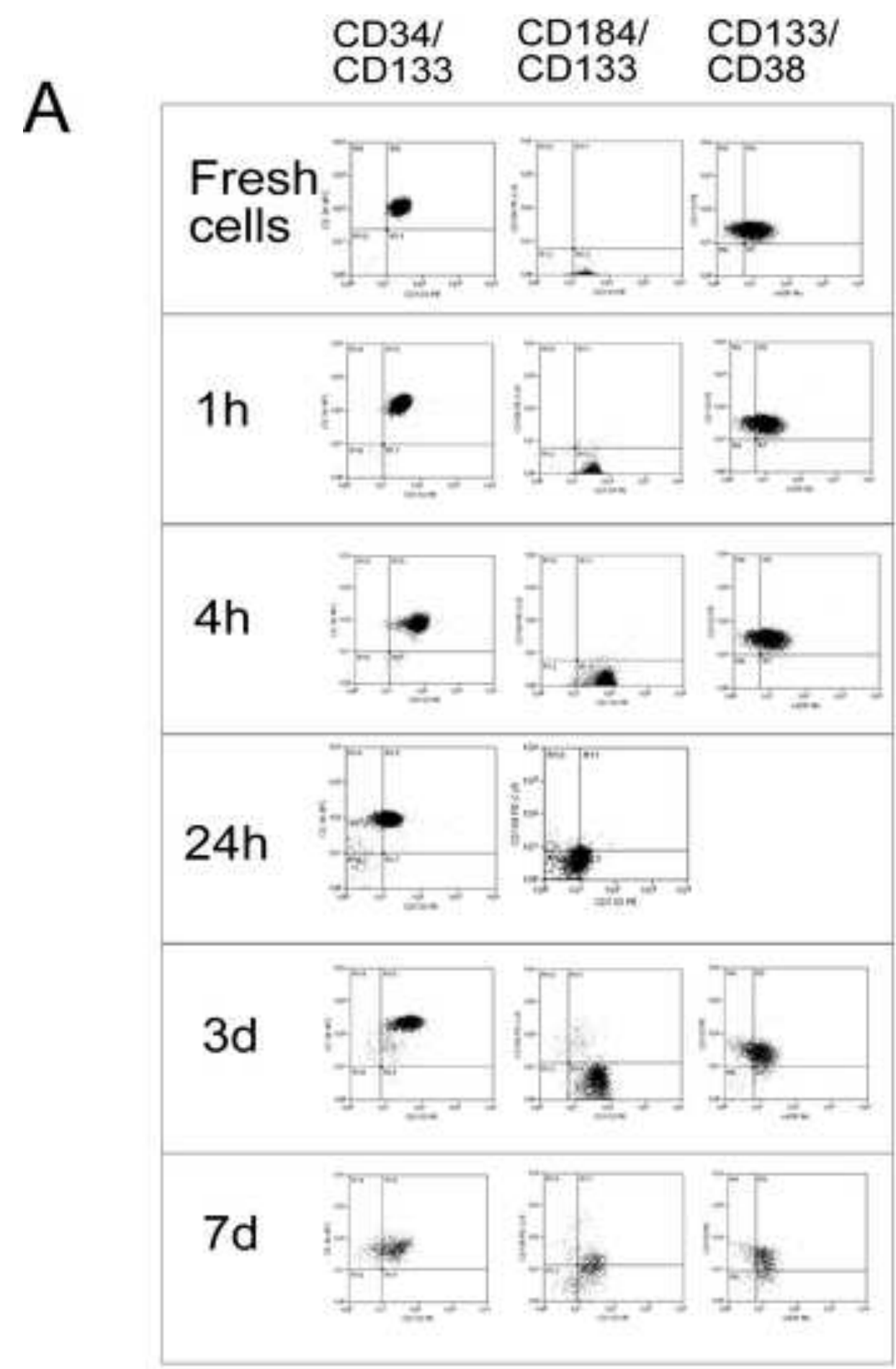

B

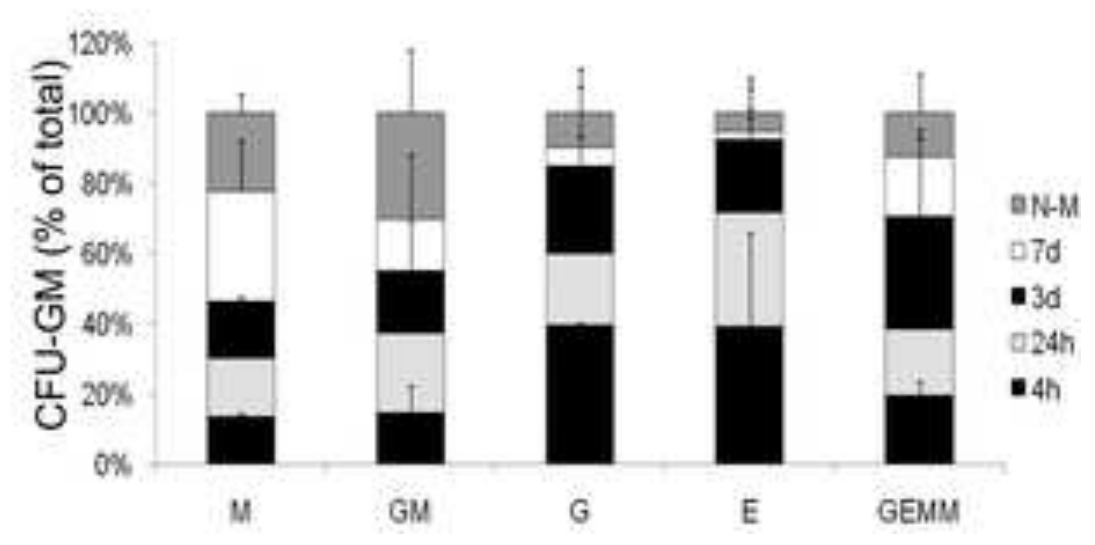




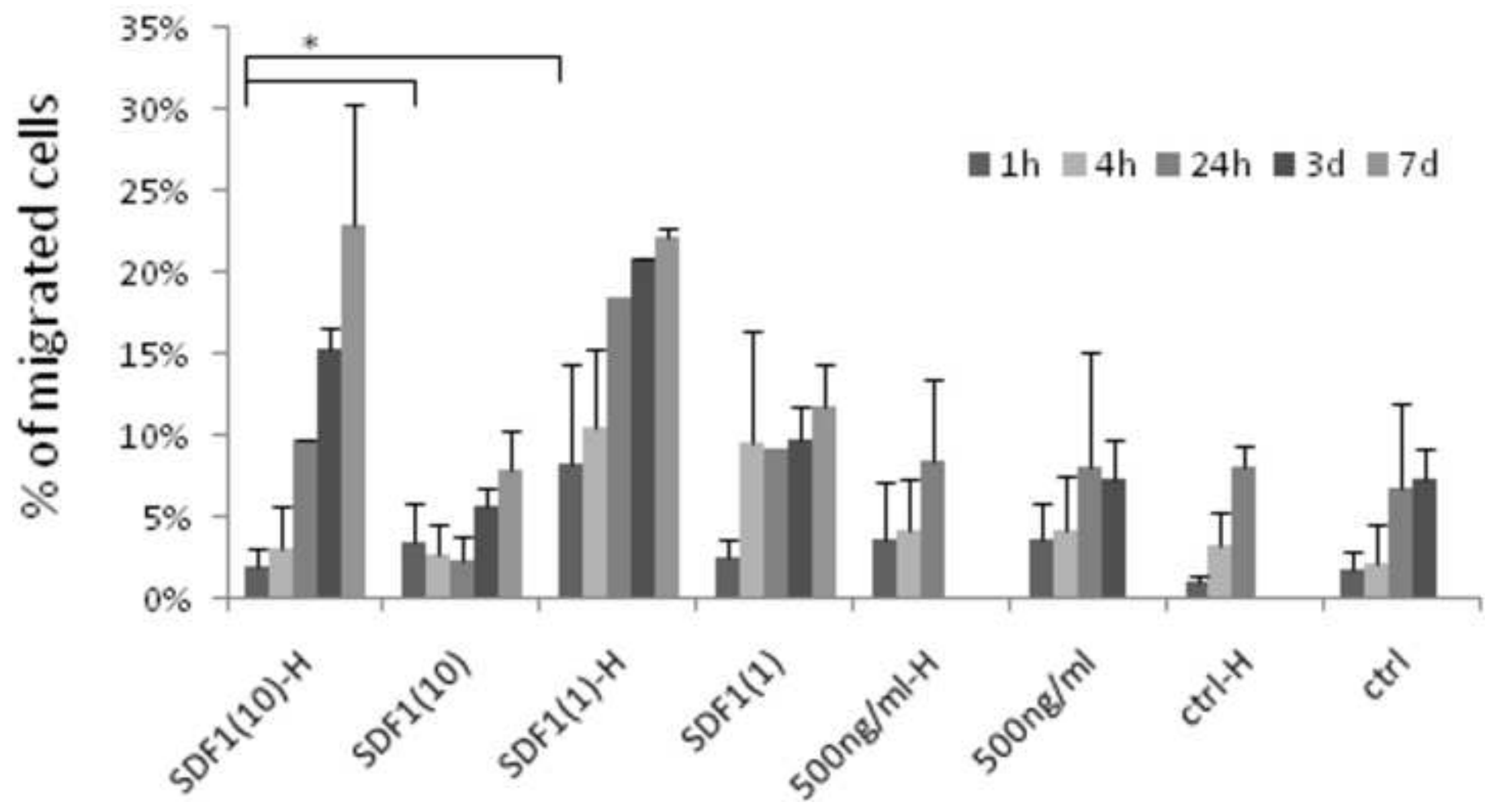

